\title{
BIAS AND THERAPIST INFLUENCE IN BEHAVIORAL ASSESSMENT
}

\author{
EDWIN J. ThOMas* \\ School of Social Work and Department of Psychology, The University of Michigan
}

\begin{abstract}
Summary-This paper illustrates several types of unwanted bias and indicates some of their adverse effects on assessment and planning for modification. Although bias and influence cannot be eliminated from the interview, their effects can be reduced by having the therapist use behaviorally neutral interviewing, informing patients early of the importance of providing accurate and specific information, and withholding recommendations and advice about modification until assessment has been completed. Occasions. when the therapist may depart from a neutral stance during assessment are noted.
\end{abstract}

DESPITE its rapid growth, the field of behavior therapy has developed unevenly. In general, more work has been done on the principles and techniques of modification than on the operational details of assessment and clinical procedure. Interviewing in behavior modification is an area particularly deserving of explication and codification. The interview is usually a principle source of information for the behavior therapist, and what the therapist says and does during assessment as well as modification may be very potent in altering the behavior of the patients. The purposes and areas of content to be covered in behavioral interviewing have been discussed by several writers (e.g. Kanfer and Phillips, 1970; Wolpe, 1969) and Wolpe has published instructive transcripts on such subjects as the identification of antecedents (Wolpe, 1970a, b, 1971a), the handling of resistance (Wolpe, 1971b) and the correction of misconceptions (Wolpe, 1971c). However, little attention has been given to interviewing technique and style, especially as they relate to interjected bias and other therapist influences that misdirect the course of therapy.

The behavior of the interviewer is of course a continuing and complex influence upon those whom he interviews. Through his eyes, face, body position, vocal expression and words the interviewer elicits emotional states, cues behavior and provides feedback that may reinforce or punish portions of the patient's verbal and non-verbal repertoire. Unwanted biases and $a d h o c$ and premature verbal interventions can be introduced all too easily during assessment. Because the interviewer provides a continuing stream of potentially active stimuli for the interviewee, the question is not how to make assessment completely neutral behaviorally, but how to reduce unwanted bias and intervention while moving toward the objective of accurate assessment. This paper identifies instances of unwanted bias and influence during assessment, suggests some ways to reduce them, and discusses forms of desirable therapist activity during assessment.

\section{EXAMPLES, TYPES AND ADVERSE EFFECTS}

The author has been impressed with what would appear to be a fairly common practice during assessment of giving ad hoc advice, interviewing in a needlessly biased fashion, and engaging in ad hoc and premature intervention. Evidence of this is to be found in published

\footnotetext{
*Requests for reprints should be addressed to Edwin J. Thomas, School of Social Work, The University of Michigan,
} Ann Arbor, Michigan 48104. 
transcripts of behavioral interviews, selected articles that describe aspects of assessment procedure, case studies, audio and visual tapes, and the practices of students and practicing behavior therapists as evidenced in consultation, reports and supervision. The examples given below are not intended to be comprehensive, but they do illustrate several different types of unwanted bias and influence.

\section{Example 1}

Patient: "I enjoy the swinging life."

Therapist: "Is that right?"

Commentary: Even if the therapist had not expressed amazement or surprise in the vocal or non-verbal aspects of his behavior, his words were literally a question and could of course be construed as expressing reservation or objection.

\section{Example 2}

$P t$ : "Oral-genital sex makes me very anxious." $T$ : "What's wrong with oral-genital sex?"

Commentary: This question directly challenges the patient and very nearly is the equivalent of saying that there is nothing wrong with oral-genital sex. The expression of this value judgement may be totally unnecessary and, in fact, may serve to inhibit the patient from describing openly what it is about oral-genital sex that makes him anxious. If one objective of assessment is to learn about what makes the patient anxious, then more information should be sought about the eliciting stimuli for the anxiety and nothing should be done to inhibit the reporting of this information.

\section{Example 3}

Pt: "I had a nervous breakdown 2 months ago and $I$ was in the hospital for ..." (therapist interrupts).

Commentary: If this area of information is relevant to the interviewer's objectives, his interruption may suppress subsequent responding on this subject.

\section{Example 4}

$T$ : "Let me ask you something about your frigidity. What do you think it does for you?"

Commentary: The therapist's question of course presumes that the frigidity actually has consequences of a given sort, which need not be the case. It is a "loaded" question.

\section{Example 5}

$P t:$ "I don't enjoy the company of my children."

$T$ : "You mean to say that you don't get anything at all out of your children?"

Commentary: The therapist's question expresses some disbelief in what the patient said and is an inappropriate way to obtain additional information on the subject of the possible aversive and non-aversive features of children for the patient.

\section{Example 6}

$T$ : "In other words, by drinking excessively you get back at your wife. Is that what you're saying?'

Commentary: Assuming that this was not precisely what was in fact said by the patient and that the therapist was making a presumption, it is a very biased question that could lead to a distortion of patient responses. The operant functions could be obtained by less biasing methods.

\section{Example 7}

$T:$ "When you hurt yourself, do you have a sexual orgasm?"

Commentary: The question should be asked in a more open-ended way to find out the possible range of reactions concerning what happens when the patient hurts himself. A direct question such as this might be appropriate, if at all, under very particular conditions such as when the patient had already indicated that sexual feelings of at least a fairly intense sort were aroused by hurting himself. 


\section{Example 8}

$T:$ "Why do you discipline your children so harshly?"

Commentary: This is a variation of the proverbial "Do you still beat your wife?" The implied criticism puts the patient on the defensive.

\section{Example 9}

$T$ : "Behavior therapy has had a dramatic record of success with problems of alcoholism and 1 am confident we can cure you of your drinking problem."

Commentary: This optimism is much more than is justified by the research on the effectiveness of behavior therapy with problems of alcoholism and could lead to false optimism and to later disappointment or resentment.

\section{Example 10}

$T$ : "When was the last time you had to discipline your son? How often do you discipline him? What did he do?"

Commentary: Because the answers to each of these questions would probably be different, it would be preferable to ask them separately.

\section{Example 11}

$T$ : (In the first interview with client just after he had described problems of child management) "You should try rewarding your children for the good things they do and ignoring the bad ..."

Commentary: If this were a noncontracted area, the advice would be ad hoc, and if the assessment had not been completed, the advice would be a premature intervention.

\section{Example 12}

$T$ : (In the first interview with marital partners) "Now I would like each of you to indicate four ways in which you would like to have your partner change and then we will proceed from there to work out a contract by which you would agree to do some of the things your partner wanted in exchange for having him do things you want done."

Commentary: Formation of a contingency contract or an exchange arrangement prior to the completion of assessment presumes information concerning the nature of problems, the controlling conditions, and the behavioral and environmental resources that may be entirely unjustified and unwarranted.

From examples such as these it is evident that there are several important types of bias and influence, and each can have adverse consequences. Information may be distorted, the negative or problematic aspects of behaviors can be emphasized at the expense of obtaining information about pro-social features; the flow of information may be interrupted; the patient may be hurried by the interviewer's pace or questions; there may be excessive dwelling on a given topic; there may be questioning of the validity and the accuracy of the patient's information; and there may be selective attention to some and not other aspects of what the patient says.

Labeling of client behavior, whether done subtly or blatantly, may create problems where there were none before, exacerbate existing problems, or contribute to the fulfillment of labeling prophecies. A false attribution of cause, in addition simply to being incorrect, may alter greatly the way the patient behaves toward himself. A false representation of behavior therapy may lead to an incorrect commitment of the client to pursue therapy when a more accurate representation might not have encouraged him to continue. False hopes may later produce disappointment and resentment. The providing of ad hoc advice or attempting modification is premature and unwarranted if an assessment has not been completed. In cases not involving crises, careful assessment is mandatory in order to formulate rationally a modification plan and to select the appropriate techniques of modification. 


\section{TOWARD LESS BIAS AND UNWANTED INFLUENCE}

The objectives of assessment include obtaining the requisite information so that planning and modification can be undertaken, establishing the contract regarding the problem area upon which to work, and conveying information about behavior therapy and the regimen the patient is likely to experience. Behaviorally neutral interviewing is one way to increase the likelihood of meeting these objectives satisfactorily. While such interviewing does not guarantee the reduction of unwarranted influence, the verbal features of what the interviewer says can be freed from most if not all distortion. Questions asked in a neutral way without biasing vocal inflection can greatly increase the likelihood of undistorted information. The interviewer should not interrupt, hurry, pace the interview too rapidly, and should let the interviewee finish what he is saying before going on to the next question. It is also desirable to explain to patients that information will be collected and appraised during assessment and that the therapist will delay making recommendations and giving advice until the assessment has been completed. As part of this socialization of the patient, it should further be indicated that accuracy, specificity and frankness are required. $A d$ hoc and premature advice should in fact be avoided until modification is undertaken. Behaviorally neutral interviewing can be done without losing a lively give-and-take or a pleasant and friendly relationship.

\section{ACCEPTABLE BEHAVIORAL ACTIVITY}

There are times when the interviewer should intentionally engage in influence to facilitate therapeutic objectives. Thus, it is generally necessary to cue and guide topics in the interview, following an agenda to be covered.* The interviewer's demeanor to patients should be friendly, civil, and courteous. The contract to work in the given problem area should be maintained as should cooperation within the regimen. Other activities that call for departures from strict neutrality involve socialization of the patient and the reinforcement of appropriate behavior, such as that needed for the production of good data. There are, of course, occasionally crises that require the therapist to give advice and to attempt behavior modification without having completed a customary assessment.

\begin{abstract}
*In the work that my colleagues and I have done on procedural guidelines for behavioral practice in open settings, we have followed steps that very much determine the particular topics to be considered in each session. These 15 steps are as follows: (1) problem inventory; (2) problem selection and contract; (3) commitment to cooperate; (4) specification of focal behaviors; (5) baseline of focal behaviors; (6) identification of probable controlling conditions; (7) assessment of environmental and behavioral resources; (8) specification of behavioral objectives; (9) formulation of a modification plan; (10) execution of a modification plan; (11) monitoring the outcomes of intervention; (12) formulation of a maintenance plan; (13) execution of a maintenance plan; (14) monitoring the outcomes of maintenance; and (15) follow-up. (Thomas et al., 1970; Gambrill et al., 1971; Thomas and Walter, 1973).
\end{abstract}

Acknowledgement-The research upon which this report is based was supported in part by grant SRS 10-P 5602315-02 Social and Rehabilitation Service, Department of Health, Education and Welfare. I wish to acknowledge the helpful assistance of Claude L. Walter and Robert D. Carter who worked on the project from which parts of this paper were derived. I also wish to acknowledge the competent assistance in preparing the manuscript of Ms. Joyce Morgan,

\section{REFERENCES}

Gambrill E. D., Thomas E. J. and Carter R. D. (1971) Procedure for sociobehavioral practice in open settings, Social Work 16, 51-62.

Kanfer F. H. and Phillips J. S. (1970) Learning Foundations of Behavior Therapy, Wiley, New York.
Thomas E. J., Carter R. D. and Gambrill E. D. (Eds.) (1970) Utilization and Appraisal of Socio-behavioral Techniques in Social Welfare-Pilot Phase, Final report on research supported by the Department of Health, Education and Welfare, Social Rehabilitation Service, Grant SRS-CRD 425-C1-9, Ann Arbor, Michigan, University of Michigan School of Social Work. 
Thomas E. J. and WALTER C. L. (1973) Guidelines for behavioral practice in the open community agency: procedure and evaluation, Behav. Res. \& Therapy 11, $1-13$.

WOLPE J. (1969) The Practice of Behavior Therapy, Pergamon Press, New York.

Wol.PE J. (1970a) Transcript of initial interview in a case of depression, J. Behav. Ther. \& Exp. Psychiat. 1, 71-79.

WOLPE J. (1970b) Identifying the antecedents of an agoraphobic reaction: A transcript, J. Behav. Ther. \& Exp. Psychiat. 1, 299-305.

WOLPE J. (1971a) Identifying the anxiety antecedents of a psychosomatic reaction: A transcript, J. Behav. Ther. \& Exp. Psychiat. 2, 45-51.

WOLPE J. (1971b) Dealing with resistance to thoughtstopping: A transcript, J. Behav. Ther.\& Exp. Psychiat. 2, 121-127.

WOLPE J. (1971c) Correcting misconceptions in a case of frigidity: A transcript, J. Behav. Ther. \& Exp. Psychiat. 2, 251-259.

(First received 7 July 1972; in revised form 11 December 1972) 